\title{
Analysis on the Application of Micro - lesson Resources in Logistics Management Major Teaching in Higher Vocational Colleges
}

\author{
Han Teng \\ Jiangsu College of Finance and Accounting, Lianyungang, Jiangsu, \\ 222061
}

\begin{abstract}
The goal of higher vocational education is to cultivate high-quality talents with professional knowledge and professional skills so that students can better adapt to the needs of social employers when they leave the campus. With the national education departments in recent years the concern of higher vocational education, the introduction of relevant policies to support higher vocational education teaching, to the high vocational education has brought a good opportunity for development, but also to higher vocational education and teaching work Has brought challenges. With the development and popularization of network information technology, the direction of higher vocational education is pointed out. In the higher vocational education, logistics management has aroused widespread concern. Vocational education workers actively use modern information technology, logistics management and professional classroom teaching, the introduction of "micro-class" teaching model, not only to become more image-specific teaching knowledge, but also allow students to practice in the classroom, do To the combination of theory and practice teaching, to help the teaching reform of higher vocational education to open a new situation.
\end{abstract}

Keywords: Micro lesson, Logistics Management, Higher Vocational College

\section{Introduction}

Micro lesson refers to the organic combination of various teaching resources according to the new curriculum standards and teaching practice requirements to 
teaching video as the main carrier, reflecting the teachers in the classroom teaching process for a knowledge point or teaching links to carry out teaching and learning activities. With the advantages of flexibility, informatization and pertinence, the micro-course will become one of the directions of modern curriculum reform. If we can draw lessons from action-oriented learning and project teaching, we can reasonably design and apply logistics micro- The teaching of theoretical knowledge to strengthen the role, so as to effectively promote the practical effect of higher vocational logistics teaching. For teachers, the value of micro-teaching is mainly to improve teaching efficiency, teaching personality and accelerate professional growth. Logistics industry in the rapid development and continuous segmentation process, the logistics professional teachers must be highly concerned about the industry development of new trends and new trends, and presented it as fragmented knowledge points. Through the production of micro-lessons, the use of teaching techniques to improve teaching resources, and promote the innovation of teaching content, and then help teachers to strengthen teaching reflection, the idea of logistics teaching condensed in micro-class, constantly thinking to improve their professional quality. For higher vocational logistics students, micro-courses allow students to choose their own professional development direction of selective learning in solving practical problems encountered in logistics problems when targeted learning, the focus of cross-disciplinary knowledge of the key points Learning, it can help students better into the classroom teaching, improve the efficiency of lectures.

\section{Teaching Status of Logistics Management Specialty in Higher Vocational Colleges}

As we all know, the basis of students in vocational colleges is poor, lack of motivation, especially hate boring theoretical teaching, but also do not understand their own professional, simply think that logistics management professional, but is to teach people how to store goods and handling goods, Lack of interest in the professional, poor self-control.

Higher vocational college logistics management students with most vocational students, like learning more serious emotions, like more interesting courses, hate the theory of relatively strong boring course. Specific performance, students in the study of "logistics base", "procurement management" and other courses, the apparent performance of the enthusiasm is not high, lack of interest in learning, and learning "logistics equipment technology", "logistics information management" courses, students Under the guidance of teachers, operating a variety of equipment to complete a variety of tasks, and other students to complete various collaborative collaborative program, teaching good results. In recent years, higher vocational colleges have made great efforts in the core field of logistics management, including the construction of fine resources class and the construction of project teaching, but they can not get rid of the traditional teaching mode. Drugs, teaching less effective. In summary, only to completely 
break the traditional teaching mode, to fully mobilize the interest of students, to stimulate students' potential, so that they enjoy learning in the future is our vocational teaching objectives, and to complete this goal, It is necessary to use a new micro-teaching model.

\section{Contradictions in Logistics Classroom Teaching in Higher Vocational Colleges}

According to the guiding spirit of the Ministry of Education, specialized vocational schools should closely focus on regional or industrial development needs, training technical and technical personnel, so the composition of the course content, increased the proportion of practical teaching, the corresponding reduction in theoretical hours. At the same time, the rapid development of the logistics industry, smart phone \& cross-border electric business \& Internet finance and other new concepts will subvert the traditional logistics structure, logistics enterprises demand for higher talent, higher logistics students to To adapt to the needs of the market, we must master the scientific and technological methods and adapt to changes in the industry operation and management capabilities, students should have the knowledge capacity and the limited distribution of hours of conflict.

Higher vocational students are a special group, which has the unique characteristics of college students, open-minded thinking and active pursuit of trendy, with a strong sense of innovation, but also a poor learning base and lack of learning strategies and learning responsibility. However, the trend of the development of the industry requires students to build knowledge and ability to be independent learning-based, and self-learning ability is one of the important social future necessary capacity. Therefore, teachers should seize the advantages of students, through the construction of business needs in line with the professional knowledge and professional ability modules, efforts to cultivate students' self-learning ability.

With the construction and application of the three communication platforms, the traditional teaching methods are facing great challenges. The diversification of students' information acquisition channels has brought forward a new direction for the teaching level of teachers. High requirements. But in reality most of the teachers is difficult to break through the previous curriculum management system, self-reflection and lack of practical ability, often in the classroom does not relax, but also not open.

\section{Micro-curriculum trends}

Micro-curriculum content to meet industry practice, students need, not only content on the theory and thinking, social ability, innovation ability. Short-term video and optimization of interactive exercises is the carrier of micro-curriculum, 
students use the fragmentation of time, learning sites more open. And can use the relevant professional resources, to achieve everyone can learn, and gradually to the construction of open university forward. To achieve the formal classroom learning and extra-curricular informal learning unity, continuous. Pay attention to play in the classroom student self-learning, collaborative learning ability, with particular emphasis on students to elaborate and challenge ability.

Most of the teachers used to write their own lectures before class, to the classroom teaching mode. Facing the tide of informationization, teachers' teaching methods are also facing change. Professor Huang Ronghuai pointed out that the five conditions of online learning: to the real problem as a starting point to learning interest as a driving force to analytic thinking for the implicit behavior to learning activities for the explicit behavior of the experience to guide, feedback for external support. This requires teachers to change the past from the theory to the theory of teaching ideas, but from the analysis of student problems, points of interest, the industry needs to import wonderful, according to the scientific laws of cognition, the teaching of the key, difficult and doubtful core knowledge Point production into fragments, including video, audio on-demand resources to guide students thinking, cooperative learning, brainstorming. Teachers in the process of adapting to information-based teaching constantly updated concepts, thinking and improving teaching behavior.

The introduction of micro - curriculum teaching will break through the limitations of textbooks and classroom teaching and realize the diversification of learning situation. The micro curriculum has the usability sense, the usefulness perception, the joyful perception, may the miniature knowledge pulse, under the corresponding work and the discussion support, obtains the better teaching effect than the long time class. Micro-teaching will change to teacher-centered to student needs as the center; students in the micro-learning to change the traditional passive learning into active learning. At present, there are three problems in the development of micro-curriculum: the form of a single, most of the usual teaching process will be recorded into a short video; topics larger; awareness is not sufficient. As an educator, we should continue to explore the innovative teaching model with scientific and full enthusiasm.

\section{The Application of Micro - Curriculum Mode in Logistics Management Specialty Teaching in Higher Vocational Colleges}

Micro-teaching mode of pre-class learning content is based on pre-school teachers to provide curriculum micro-class site address, the Internet will be watching the content of micro-video and courseware to learn, self-learning. In the pre-class teachers need students to assign the appropriate learning tasks, students according to the teacher assigned tasks to watch micro-video, the effect is better. Such as "logistics equipment and technology" courses involved in the cattle to introduce, you can let students go online to watch the micro-class video of cattle 
operations, the students have seen the video after the cattle will certainly have an intuitive impression, Teachers in the classroom and then introduced the structure and function of cattle, the students will quickly understand.

Teachers in the classroom for students to check the content of pre-class learning, the specific approach can be made and micro-video-related issues, let the students group to explore and guide students to work together to solve the problem, and then summarize the conclusions drawn by the students, And the students to evaluate the results achieved. Students through the micro-video questions to analyze the problem - to solve the problem is actually the process of learning the internalization of knowledge, and teachers by accepting feedback on the micro-video evaluation summary is actually improve the teaching methods to improve the teaching level process.

Higher vocational college logistics management mode of micro-class want to really achieve, it must have a scientific and reasonable and can be implemented assessment methods. At present, there are many colleges and universities in the world to open courses, such as Harvard University, Stanford University, their assessment approach is that learners in each online course to learn after the online check-in, as the attendance assessment, Of the assessment is still using the traditional curriculum assessment model, such as online volume, answer and other assessment methods. However, I think that such assessment methods do not meet the learning characteristics of vocational students.

We can vocational logistics management curriculum content into a number of modules or knowledge points, and then these knowledge points can be produced into a micro-video can be displayed, for example, we can "logistics information technology transfer," the knowledge points into use QQ, MSN, WeChat and other communication software to complete the process of micro-video transmission of information, students can watch the video in accordance with the requirements of the video in the video display technology, the teacher can be identified this student knowledge points have passed the examination. For vocational students, the examination is not limited to papers, not limited to the classroom, students can do whatever they want, to complete the requirements of the course knowledge points, can be assessed.

As China's economic restructuring and development, the number of logistics managers and the quality of the demand is also rising, but there are not satisfied with the logistics industry to recruit talent, logistics graduates difficult job dilemma. The reason is that the construction time of logistics specialty is short, the knowledge system of professional education is not systematic, the content of some courses is duplicated, and it is out of line with the practical application of the industry. It has not grasped the characteristics of interdisciplinary, heavy practice and heavy ability of logistics management. In order to adapt to the logistics management professional teaching to the application of technology transition, combined with the micro - curriculum teaching mode to promote the application. Teachers should have a deep understanding of industry and enterprise work tasks and work processes, to understand the talents of enterprises in the professional, social and methodological capacity and other aspects of 
specific requirements. These requirements and curriculum links, design theme clear, targeted micro-curriculum.

The content on the theme of a clear, logistics-oriented work flow-oriented. In view of the characteristics of the logistics specialty, such as systemic, process, interdisciplinary and operational, the subject of professional microcurriculum is clear in content selection, insisting on the principle of combination of national occupational standards and actual needs of enterprises, and the practicality of logistics post work flow Content-oriented. So that students in-depth understanding of the work flow of different logistics positions, the need for professional skills and professional ethics. The content does not pursue the systematic coverage of content, can independently assume the complete knowledge content.

\section{Conclusion}

With the gradual popularization of the micro-teaching model, more and more people will feel its unique superiority, and also provide a good direction for the reform of higher vocational education. The combination of "logistics cost management" and "micro - class" teaching, effectively aroused the interest of students and promotes the transformation of higher vocational education teaching mode, improve the efficiency of education and teaching to achieve the teaching objectives of higher vocational education.

\section{References}

[1] Zheng Xiaojun, Zhang Xia. Six questions and responses to micro-teaching [J]. Modern Distance Education Research, 15(3), pp. 14-23, 2014

[2] Zhong Qi, Wu Zhiyong.Computer Fundamental Curriculum "microcurriculum" teaching mode research [J]. Modern Educational Technology, 12(3), pp. 32-41, 2014

[3] Liu Hongxia, Zhao Wei, Chen Lei. Based on "microcurriculum" ontology characteristics of teaching behavior design and practice reflection [J]. Modern Educational Technology, 2(4), pp. 14-23, 2014

[4] Zhang Xiaojun, Li Yaqin, Wang Haoyu, Ding Xuemei. Micro lesson multimedia courseware design from the perspective of cognitive load theory [J]. Modern Educational Technology, 4(3), pp. 87-91, 2011

[5] Yu Shengquan, Chen Min.Micro-Course Design based on Learning MetaPlatform [J] .Journal of Open Education, 8(3), pp. 102-105, 2014 